\title{
FOREIGN LANGUAGE READING ANXIETY AMONG INDONESIAN EFL SENIOR HIGH SCHOOL STUDENTS
}

\author{
Azhari Muhlis \\ Sebelas Maret University, Surakarta \\ arimuhlis92@gmail.com
}

\begin{abstract}
This study aims to investigate foreign language reading anxiety among Indonesian EFL Senior High School students. Thirty twostudents of grade eleven in a senior high school in Bandung were involved as the participants. This study employed a survey research design. The data was collected by two types of questionnaires. The first finding revealed that most of the students perceived anxiety in medium level $(71,9 \%$ students admitted). The second finding found that there were two major potential factors of foreign language reading anxiety namely text features and personal factors. Under the concept of text features, there are three sources of foreign language reading anxiety including unknown vocabulary $(49 \%$ students agreed), unfamiliar topic $(40 \%$ students agreed), and unfamiliar culture (38\% students agreed). On the other hand, under the concept of personal factors, there are two sources of foreign language reading anxiety including fear of making errors $(39 \%$ students agreed), and worry about reading effects $(28 \%$ students agreed).
\end{abstract}

Keywords: Foreign Language, Reading Anxiety Senior High School Students,

\section{INTRODUCTION}

Nowadays, literacy plays important role in education field. According to Cameron (2001), such activities, in which reading and writing are involved are called "literacy event." The literacy event should be enrolled in teaching and learning processes especially reading skill that has to be mastered by the students in dealing with national examination later. 
In fact, teaching students to read English text is not an easy thing. Based on preliminary study in a senior high school in Bandung, there were some problems experienced by students in reading activities at English as Foreign Language (EFL) classroom, for instance, some students avoid activities in English reading class, or at least, they are not enthusiastic toward reading in English and in some cases they are avoid reading English materials (Jalongo \&Hirsh, 2010). These manifestations are symptoms of foreign language anxiety in classroom (Horwitz, Horwitz, \& Cope, 1986). In some cases, foreign language reading anxiety has negative effect on reading comprehension and process (Saito, Horwitz, \& Garza, 1999; Sellers, 2000).

In Indonesian context, researcher has noted that most research in FL anxiety has been conducted mainly on speaking, since speaking has long been viewed as the most anxiety-provoking skill for foreign language learners to acquire (Horwitz et al., 1986). As a result, very little research has been conducted on FL reading anxiety in Indonesian context, as can be observed from the prevalent use of the Foreign Language Classroom Anxiety Scale (FLCS) in FL anxiety research conducted in Indonesia. Developed by Horwitz et al. (1986), the FLCAS was mostly used to investigate listening and speaking anxiety (Saito et al., 1999). There is a need to investigate foreign language reading anxiety, particularly in Indonesian context because the acquisition of foreign language is not only limited to the speaking skill. The acquisition of FL reading skill is important as well, especially in academic contexts, where the successful learning is preliminarily determined by one' s ability to read (Grabe, 2009; cited in Liu, 2011).

Furthermore, from a review of previous studies on FL reading anxiety shows that most of previous studies concerning on examining the relationship between reading anxiety and reading performance (Brantmeier, 2005; Kuru-Gonen, 2007; Saito, et.al., 1999; Sellers, 2000). How anxiety affects foreign language performance is only one issue to consider when discussing anxiety and language learning. There are other important issues that need to be considered for a better understanding toward the phenomenon of FL reading anxiety such as investigating different level of FL reading anxiety among students, and potential factors 
that cause FL reading anxiety. Those are related to the scope of this present study and to what extent this study is conducted.

Next, with respect to the selection of participants, the majority of participants recruited in previous reading anxiety studies were actually from university level. To understand how high-school students perceive FL reading anxiety, the recruitment of participants from high-school contexts, is therefore necessary. Therefore, the present study attempts to fill the gap and explore this kind of phenomenon in Senior High School level, especially in Indonesian setting, where English is considered a foreign language and is learned and used primarily in classroom context.

Departing from the background of the study, this study has two objectives. The first is to know the level of reading anxiety perceived by Indonesian Senior High School Students in English reading classroom. The second is to identify the potential factors that make them feel anxious when they read English text.

This study is hopefully could give some benefits both in theory and practice. In term of theoretical benefits, the results of study are expected to enrich the literature and also give beneficial references for future study in term of foreign language reading anxiety, especially in providing the information about different level of reading anxiety, and potential factors that cause reading anxiety in Indonesian EFL context.

In term of practical benefits, the results of study are expected to give more insights for teacher and student in foreign language learning and teaching, especially in reading area. The information could help teachers to understand more the different levels of reading anxiety perceived by students when they read in English. They also can get more information about the potential factors that cause foreign language reading anxiety which is considered beneficial in helping the teachers to conduct appropriate treatment regarding the reading anxiety of their students. For students, the results can give awareness toward anxiety issue in foreign language reading and anticipation towards potential factors that can trigger their anxious feeling in EFL reading. 


\section{THEORITICAL FRAMEWORK}

The literature review discusses some related theories and researches used in this article as the springboard and foundation of the study, covering the topics foreign language reading anxiety, potential factors that cause foreign language reading anxiety, and the previous studies about FL reading anxiety issue.

\section{Foreign Language Reading Anxiety}

Foreign language reading anxiety refers to feeling of worry and apprehension when students try to read and comprehend foreign language text. Zbornik (2001) defines reading anxiety as unpleasant feeling toward reading which caused by significant other disapproval in reading process. Significant otheris defined as a person or people who have a significant emotional influence over the student's behavior or belief system.

In this case, the forms of disapproval are in the form of peers or teacher pressure as the significant others. These may trigger a sense of worry about reading effect among the students, which is influenced by their peer and teacher's attitude regarding their reading performance. For example, students have made mistakes in pronunciation while reading and getting laughed by their peers and the teacher's manner in correcting their mistakes, which seems to inhibit the chance of the students to perform their reading.

Foreign language reading anxiety, mistakenly deemed by teachers and practitioners as least anxiety-provoking, had not grabbed attention of researchers until Saito et al. (1999) reveal that foreign language reading anxiety is a distinct phenomenon from foreign language anxiety in general. In their research, a new inventory to measure reading anxiety level was developed namely Foreign Language Reading Anxiety Scale (FLRAS).

Subsequently, Horwitz et al (1986, cited in Rajab et al, 2012) distinguished reading anxiety from general types of foreign language anxiety which related with oral performance. Therefore, reading anxiety is a distinct phenomenon from foreign language anxiety in general. In addition, reading can be regarded as oral performance because the learners show their individual act to interact with a text.

Like speaking, student will feel anxious when they interact with others. Meanwhile in reading process, the phenomenon of 
anxiety exists among the learner, but most learners do not realize that during the progress of reading, anxiety has been stated as one of factors which can impede the reading process. Precisely, anxiety happens when the learners try to decode or interpret a non-native language text (Saito et al. 1999).

\section{Potential Factors of Foreign Language Reading Anxiety}

The present study uses the concept constructed by Ahmad et al. (2013) who propose two broad factors of foreign language reading anxiety such as personal factors and text features. This is also in line with Alderson (2005, cited in Shariati \& Bordbar, 2009) who introduced factors that affect reading comprehension can derive from reader variables (internal to the reader) and text variables (external to the reader).

\section{Foreign Language Reading Anxiety Caused by Personal Factors}

The current study uses the concept postulated by Ahmad et al. (2013) which propose two sub factors under the concept of personal factors such as worry about reading effect and fear of making error.

\section{Worry About Reading Effect}

Worry about reading effect is the manifestation of anxiety toward reading aloud. According to Jalongo \& Hirsh (2010) reading aloud is paired with anxious unconditioned stimulus, which brings a negative reaction. The case is when the students are asked to perform reading aloud in front of their classmate, they will feel worry and disrupt concentration in comprehending a text. If they fail to control their anxious feeling, it is difficult for them to demonstrate their idea about a text. Moreover, they will forget what has been read. The anxious feeling will happen during and after the reading task. Consequently, it will disturb both reading comprehension and performance (Ahmad et al., 2013).

\section{Fear of Making Error}

Fear is substantially related with a matter of self-confidence. It is supported by several studies which stated that language anxiety is complexly intertwined with self-confidence though the latter is characterized as a positive component (Brown, 2007). In some cases, those who lack of self-confidence will be afraid to make errors in learning. Hence, the feeling of afraid to make error will lead students to be anxious in the act of reading. 


\section{Foreign Language Reading Anxiety Caused by Text Features}

The current study used the concept postulated by Ahmadet al (2013) which propose three factors under the concept of the text features such as unfamiliar culture, unfamiliar topic, and unfamiliar vocabulary.

\section{Unfamiliar Culture}

In considering reading task as a demanding activity, it is important to recognize that reading is not only interaction between the reader and the thoughts of the author, but also interaction between the reader and the shared knowledge of the cultural history in the printed materials (Tomasello, 1999; as cited in Ahmadet al., 2013). Not being familiar with English or other cultures might inhibit students' reading comprehension process and cause anxiety as the culture represented in the text is foreign to them (Rajab et al.,2012).

\section{Unfamiliar Topic}

According to Wallace (2001, cited in Kuru-Gonen, 2009), if the topic of a text is not interesting to a learner it is almost impossible for this learner to read for pleasure and consequently to become an effective reader. To put it another way, reading topic which suits with interest of a reader will elicit good response toward reading activity. It is supported by Kuru-Gonen (2009) that uninteresting topic in reading text is considered as a source of foreign language reading anxiety.

\section{Unknown Vocabulary}

According to Rajab et al. (2012), unfamiliar vocabulary might impede learners' comprehension and cause difficulty which in turn leads to anxiousness. Moreover, in this case, English vocabulary completely differs from Indonesian in terms of its pronunciation, because when the learners read English texts, the vocabulary do not exactly reflect the real pronunciation. It has been a matter for Indonesian learner to recognize the meaning of vocabulary itself. In addition, William and Dallas (1984, cited in Shariati and Bordbar, 2009) contends that vocabulary difficulty, especially the meanings of idiomatic expressions, make a text hard to read for second language readers.

\section{Previous Studies about Foreign Language Reading Anxiety}

Saito et al. (1999) as the pioneer of measuring foreign language reading anxiety by developing standardized instrument 
namely Foreign Language Reading Anxiety Scale (FLRAS). They used a five-point Likert Scale consisting of 20 items ranging from "strongly agree" to "strongly disagree". In their preliminary study, they applied two types of instrument such as foreign language classroom anxiety scale (FLCAS) and foreign language reading anxiety scale (FLRAS) to check reliability and validity. They investigated foreign language reading anxiety to 383 students enrolled in first-semester university French, Japanese, and Russian courses. With participants from different countries, they found that levels of reading anxiety vary by target language, and seem to be related to writing system. In addition, the findings also indicate that students with higher level of FL anxiety tended to have higher level FL reading anxiety and vice versa.

Horwitz et al. (1986) conducted an investigation of foreign language anxiety among 30 university students of Japanese, Spanish, and Russian. From the study, it was found that reading anxiety influenced language learning performance of the students. The finding of the study showed that those who have lower level of reading anxiety tend to perform better than those who have high anxiety. Based on the study also revealed that factor that most contribute to reading anxiety is related with writing systems.

Zhao (2008) investigated 125 learners of Chinese as a foreign language in a public university in the U.S. The study gave some insights about some potential factors of reading anxiety such as unfamiliar scripts, unfamiliar topics, and worry about reading effect. The study employed correlational method which found that reading anxiety and foreign language reading performance have a significant negative correlation. The result shows that reading Chinese text is anxiety-provoking to learners of non-western language like speaking activity.

Sellers (2000) investigated 89 university students from a third semester course and from an intermediate level conversation course in Spanish at university level. The study indicated that reading anxiety is a distinct variable in foreign language learning. Interesting result was found when the students felt anxious when they were asked to read in L2 compare with other activities. High anxious students tend to recall less passage content than those who belong to low anxious student. 
Young (2000) investigated second year Spanish. The study found that there is negative correlation between high reading anxiety and recalls of learners. In the study, the instrument such as magazines, newspaper, etc. were employed. The result is still similar with the previous studies which found interrelationship between high reading anxiety and low proficiency in L2 reading comprehension.

The findings from those previous research revealed that most studies which investigated phenomenon of reading anxiety concern more on investigating correlation between reading anxiety and reading performance by using correlation method. Investigating the degree of reading anxiety and potential factors of foreign language reading anxiety are still new area of study especially in Indonesian EFL context.

Therefore, the position of present study attempts to fill the gap and explore this kind of phenomenon in Indonesian EFL Senior High School context by using survey study and also the findings from those previous research will be compared with the finding in this research as an addition in the discussion of this research.

\section{RESEARCH METHODOLOGY Research Design}

To accommodate the investigation toward foreign language reading anxiety among Senior High School students, this study was guided by a survey research design. According to Nunan (1992, as cited in Marungudzi, 2009) stated that "where a snapshot of conditions, attitudes, or events at a single point in time" need to be taken, the survey research design is the most suitable method. The survey research design is also suitable for this study because it provides "a broad overview of a representative sample" (Mouton, 2001, as cited in Marungudzi, 2009).

It is also asserted by Creswell (2012) that survey designs belongs to type of quantitative research that requires questionnaire distribution to representative of population (sample) to determine inclination of behaviors or characteristics of population. This kind of method had been commonly employed in previous studies related to foreign language anxiety (Horwitz, et al., 1986; Saito et al., 1999). By conducting a survey, all the data gained from the questionnaires were conveyed through descriptive 
statistics. Descriptive statistics is a medium for describing survey data in manageable form (Babbie, 1973).

\section{Sample of Study}

To gather the data of the current study, purposive sampling was employed in selecting the sample of study. The researcher intentionally selected the participants to achieve the objective of the study (Creswell, 2009). The population of study was students from a senior high school in Bandung.

From the first to the third grade, 32 second grade students were chosen to be the sample of studyby using purposive sampling with several criteria such as attitude toward English class, English reading proficiency, capability in representing idea, and accessibility during the study. After the data from the S questionnaire was collected, and the students' reading anxiety level was determined.

\section{Research Instruments}

In order to measure the level of reading anxiety, the questionnaire used is the adaptation and translation of FLRAS (Foreign Language Reading Anxiety Scale) developed by Saito et al. (1999). They also found that FLRAS shows good internal reliability with internal consistency coefficient of .86 (Cronbach Alpha, $\mathrm{n}=383$ ), the reliability score is relatively good compared to other instrument such as FLCAS with the score .94. FLRAS, in its function to measure the level of reading anxiety perceived by foreign language learners has also been used by some researchers such as Cetinkaya, 2011; Kuru-Gonen, 2005, 2009; Shariati \& Bordbar, 2009; Zhao, 2009).

FLRAS consists of 18 items (two items deleted from the original scale as a result of reliability and validity studies) with answers response option ranged from Strongly Agree, Agree, Neither Agree nor Disagree, Disagree, and Strongly Disagree. Therefore, if the points are summed up by adding each answer score of each statement, the score of students" reading anxiety scale would range from 18 to 90 . The high score represents the high level of reading anxiety.

Subsequently, for measuring the potential factors of reading anxiety, the questionnaire utilized is the adaptation and translation of a developed questionnaire proposed by Ahmad et al (2013). It was used to investigate potential factors of reading anxiety in 
Jordanian EFL context. The validity of the instrument has been checked by giving to a jury of two doctors from the education department, five teachers from the language center, and two $\mathrm{PhD}$ students in the field of foreign language teaching to review and comment on the layout and the statement.

Finally, from 40 items proposed,26 items were selected as the items of questionnaire. The instrument looked right, which reflected high quality of face validity and content validity. In relevance to reliability of the instrument, by using Cronbach Alpha, the reliability coefficient the final version of the instrument was 0,846 , which still indicates the acceptable value in the educational research. This instrument is intended to investigate the trend of the potential factors of foreign language reading anxiety among foreign language learners.

\section{Data Collection}

Firstly, two types of questionnaire were distributed to 32 Second Grade Senior High School Students in different meeting. Secondly, the administered questionnaires were collected and the data from PLSPQ questionnaires were analyzed by using SPSS to determine the mean and standard deviation score as matter of consideration to categorize the level of reading anxiety, and the second questionnaire was analyzed manually to determine the percentage of each item on the questionnaire as criterion to determine the dominant factor that causes reading anxiety. Lastly, based on the result of analysis of reading anxiety level, students' answer from FLRAS questionnaire, and a developed questionnaire by Al-Shboul et al. (2013) were analyzed using some experts' theory and compared with some studies results.

\section{Data Analysis}

In order to answer the research questions, a descriptive analysis was conducted. Descriptive analysis refers to summarizing the data as well as the results and reporting these results in frequencies, percentage, means (average), and measures of variability such as standard deviation (Johnson, 1992). In this study, descriptive analysis was computed to obtain the data about the anxiety level perceived by the students in reading English, and their potential sources of anxiety in reading English. 


\section{DATA FINDINGS AND DISCUSSIONS \\ Students' Reading Anxiety Level}

This section presents the relevant data to the first research question which is students' reading anxiety level. It provides participant's response towards 18 FLRAS questionnaire items. Table 1 displays the descriptive statistics of the levels of reading anxiety of all participants. The level of reading anxiety for each participant is represented by the total score of every items (the sum of 18 items), and the possible range is 18 to 90 . In this present study the score range was between 42 and 71 based on the table below.

Table 1. Descriptive Statistics for Reading Anxiety for the Total Sample

\begin{tabular}{cccccc}
\hline & $\mathbf{N}$ & Min & Max & Mean & SD \\
\hline Total & 32 & 42 & 71 & 55,6 & 6,9 \\
\hline
\end{tabular}

The thirty two students were classified into three different groups. Following Kuru-Gonen (2007) criteria, the levels of students" reading anxiety were categorized into Low, Medium, and High. Students with high anxiety were those whose score on FLRAS was higher than the calculation of Mean + Standard deviation score based on the table 4.1 above.

Furthermore, it can be seen in Table 4.2 below, students with scores $>63$ were considered to have a high level of reading anxiety. Secondly, students with low anxiety were those whose score on FLRAS was lower than the calculation of Mean - Standard deviation score. They were the students with scores $<49$. Finally, students whose score on FLRAS were between those two score were considered to have a medium level of anxiety. They were students whose scores were between 49 and 63 .

From the formulation above, the ranges of RA score in this current research were described in the table 2 below.

Table 2. Levels of Reading Anxiety

\begin{tabular}{cc}
\hline Level & Range \\
\hline Low level & $<49$ \\
Medium level & $49-63$ \\
High level & $>63$ \\
\hline
\end{tabular}


To examine the distributions of the reading anxiety levels, the frequency of the scores of reading anxiety falling within each category was calculated. The result shows that six participants (18, $7 \%$ ) fell in the low level, 23 participants $(71,9 \%)$ that fell in the medium level, and three participants $(9,4 \%)$ fell in the high level (See Figure 1).

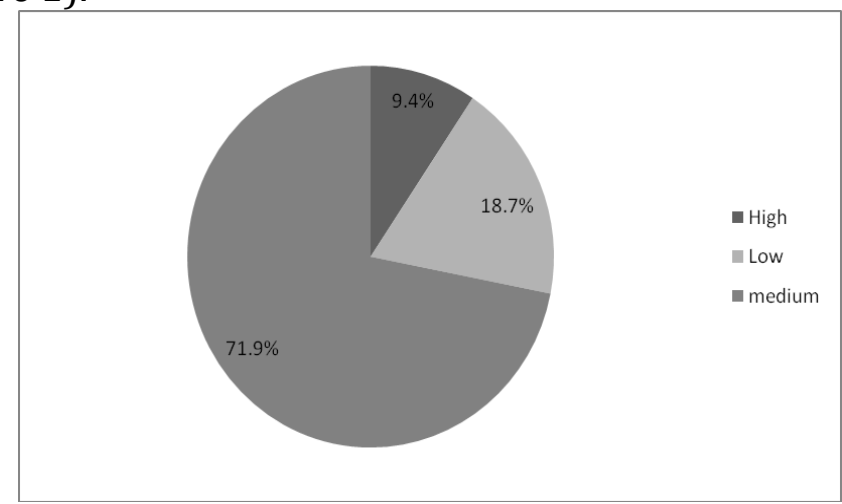

Figure 1. Reading Anxiety Level Distribution

The distribution suggested that over half of the participants reported to be at medium level of reading anxiety with percentage of $71,9 \%$. The result showed that reading anxiety perceived by the students in an English classroom was prevalent as only six students $(18,7 \%)$ who fell in the low level. Such finding is consistent with Saito et al. (1999), Sellers (2000), Lee, (1999), who revealed that reading anxiety actually does exist and rejected the theory by Horwitz et al. (1986) who contends that foreign language anxiety center the difficulties caused by anxiety with respect to oral performances.

It is understandable if Indonesian learner find reading as an anxiety-provoking task, since the learners not only deal with unfamiliar spelling patterns, sentence structure, syntax, lexicons, and other complex semantic relations, but also cultural background knowledge in making meaning from text (Rajab et al., 2012)." It is described more that anxiety happens when the learners try to decode or interpret a non-native language text (Saito et al. 1999).

Several studies that investigate student's anxiety in reading English text show almost similar result. For example, Kuru-Gonen (2007) and $\mathrm{Wu}$ (2011) found most of their participants were in the medium level of anxiety. For example, Wu (2011) found out 60 out 
of 91 participants fell in "medium" level of reading anxiety (69, $2 \%$ ). These studies indicate that anxiety inhabited students who learn English especially when they attempt to comprehend English text. Therefore, this study must agree to what $\mathrm{Wu}$ (2011) said that in spite of students' anxiety level, these anxious language learners should get serious attention from the teachers. EFL teacher should cope with student's anxiety in order to improve reading comprehension performance of the students.

\section{Potential Factors of Students' Reading Anxiety}

The potential factors of reading anxiety were analyzed from students' answers toward 26 items in the developed questionnaire by Ahmad et al. (2013). From the questionnaire given to the participants, some potential factors of foreign language reading anxiety were found. These potential factors of reading anxiety are arranged in table 4.3 ranging from the most frequent to the less, descriptive statistics were used to present the results.

Table 3. The Percentage of the Specific Domains of the Potential Factors of Foreign Language Reading Anxiety

\begin{tabular}{|c|c|c|c|c|c|c|}
\hline Range & Themes & $\begin{array}{l}\text { D \& } \\
\text { SD } \\
\end{array}$ & $\mathbf{N}^{*}$ & $\begin{array}{c}\text { A \& } \\
\text { SA }\end{array}$ & $\operatorname{Rank}^{* *}$ & Aspects \\
\hline $1-6$ & $\begin{array}{l}\text { Unknown } \\
\text { Vocabulary }\end{array}$ & $10 \%$ & $41 \%$ & $49 \%$ & 1 & \multirow[t]{3}{*}{$\begin{array}{c}\text { Text } \\
\text { Features }\end{array}$} \\
\hline 7-10 & $\begin{array}{l}\text { Unfamiliar } \\
\text { Topic }\end{array}$ & $16 \%$ & $44 \%$ & $40 \%$ & 2 & \\
\hline $11-15$ & $\begin{array}{l}\text { Unfamiliar } \\
\text { Culture }\end{array}$ & $18 \%$ & $44 \%$ & $38 \%$ & 3 & \\
\hline $16-20$ & $\begin{array}{c}\text { Fear of } \\
\text { Making Errors }\end{array}$ & $15 \%$ & $46 \%$ & $39 \%$ & 1 & \multirow[t]{2}{*}{$\begin{array}{c}\text { Personal } \\
\text { Factors }\end{array}$} \\
\hline $21-26$ & $\begin{array}{l}\text { Worry about } \\
\text { reading effect }\end{array}$ & $20 \%$ & $52 \%$ & $28 \%$ & 2 & \\
\hline
\end{tabular}

Note:

* $\mathrm{N}=$ neither disagree nor agree; $\mathrm{A} \& \mathrm{SA}=$ agree and strongly agree; $\mathrm{D} \& \mathrm{SD}=$ Disagree and Strongly Disagree

** Rank was determined based on the percentage of participant who choose strongly agree and agree toward the questionnaire items

The table above showed the potential factors of students' reading anxiety in EFL classroom. Being asked directly from the 
questionnaire, the students showed that their potential factors of anxiety in reading related to Ahmad et al. (2013) theory.

Under the aspect of text features, it was found that $49 \%$ of the participants agree with unknown vocabulary that mostly causes reading anxiety. Furthermore, unfamiliar topic was ranked as the second most frequent factor of reading anxiety with $40 \%$ of the participants agree with the factor. Then, unfamiliar culture was ranked as the least frequently source of anxiety with $38 \%$ of the participants agree with the factor.

Subsequently, under the aspect of personal factors, it was found that $39 \%$ of the participants were anxious because of fear of making errors. Furthermore, it was found that $28 \%$ participants were anxious because of worry about reading effect.

\section{Unknown Vocabulary}

Table 4 below will represent item description related with unknown vocabulary aspects and frequency distributions in percentage of each item.

Table 4. The Percentage of Unknown Vocabulary Items

\begin{tabular}{|c|c|c|c|c|c|c|}
\hline & Item Description & 1* & 2 & 3 & 4 & 5 \\
\hline \multirow[t]{2}{*}{1} & When I am reading in & 0 & 5 & 6 & 18 & 3 \\
\hline & $\begin{array}{l}\text { English, I get very } \\
\text { upset and worried } \\
\text { whenever I encounter } \\
\text { strange vocabulary. }\end{array}$ & $0 \%{ }^{* *}$ & $15,62 \%$ & $18,75 \%$ & $56,25 \%$ & $9,37 \%$ \\
\hline \multirow[t]{2}{*}{2} & I focus on words in & 0 & 4 & 20 & 7 & 1 \\
\hline & $\begin{array}{l}\text { because if I know the } \\
\text { terms, I can } \\
\text { understand the text }\end{array}$ & $0 \%$ & $12,50 \%$ & $62,50 \%$ & $21,87 \%$ & $3,12 \%$ \\
\hline \multirow[t]{2}{*}{3} & I feel anxious in & 0 & 4 & 15 & 10 & 3 \\
\hline & $\begin{array}{l}\text { reading English when I } \\
\text { encounter series of } \\
\text { three strange words. }\end{array}$ & $0 \%$ & $12,50 \%$ & $46,87 \%$ & $31,25 \%$ & $9,38 \%$ \\
\hline \multirow[t]{2}{*}{4} & I enjoy reading a text & 0 & 0 & 9 & 21 & 2 \\
\hline & $\begin{array}{l}\text { in English when I } \\
\text { know its translation. }\end{array}$ & $0 \%$ & $0 \%$ & $28,12 \%$ & $65,62 \%$ & $6,25 \%$ \\
\hline \multirow[t]{2}{*}{5} & I do not like to read an & 0 & 1 & 9 & 20 & 2 \\
\hline & $\begin{array}{l}\text { English text that has } \\
\text { lots of difficult words. }\end{array}$ & $0 \%$ & $3,12 \%$ & $28,12 \%$ & $63,00 \%$ & $6,25 \%$ \\
\hline \multirow[t]{2}{*}{6} & When I am reading in & 0 & 5 & 19 & 7 & 1 \\
\hline & English, I feel upset & $0 \%$ & $15,62 \%$ & $59,37 \%$ & $22,00 \%$ & $3,12 \%$ \\
\hline
\end{tabular}




\section{and anxious if I}

encounter strange

vocabulary.

Note:

* 1 =strongly disagree; 2 =disagree; 3 =neutral; 4 =agree; 5 =strongly agree

** The frequency in percentages was rounded to the nearest whole number

Based on the developed questionnaire proposed by Ahmad et al (2013), items 1-6 revolved around unknown vocabulary theme. It was found that 21 student (66\%) agreed with item 1, which means that unknown vocabulary creates anxiety towards reading in the English language which ultimately lessens the students' comprehension of English reading materials. 8 students (25\%) confirmed item 2, which can be understood that students refer to vocabulary in reading as an important matter they must acquire to avoid reading anxiety in the English language. Then, 13 students (41\%) confirmed item 3, which can be concluded that not only knowing a word causes anxiety in reading English but also the unknown surrounding words make the act of reading more anxious and challenging.

Subsequently, 22 students (72\%) confirmed item 4, which can be acknowledged that reading can be enjoyable task if all vocabulary were comprehended. The students also thought that clearly vocabulary matters which cause reading anxiety in dealing with English text as represented by 22 students (69\%) confirmed item 5 and 8 students (25\%) confirmed item 6.

The findings show the great number of anxious students who consider that unknown vocabulary as the biggest factor that causes reading anxiety under the aspect of text features. The result of this study is in accordance with the study conducted by Saito et al. (1999) who found that students' level of anxiety is very much related to the writing systems, including unknown vocabulary.

Furthermore, unknown vocabulary was categorized to be one of five themes of anxiety caused by reading texts in the study of Turkish students who were learning English language as a foreign language (Kuru-Gonen, 2009). It means that unknown vocabulary has been a main problem among foreign language learner in different context. . Subsequently, Rajab et al. (2012) convince that 
unfamiliar vocabulary might impede learners' comprehension and cause difficulty which in turn leads to anxiousness.

\section{Unfamiliar Topic}

Table 5 below represents item description related with unfamiliar topic factors and frequency distributions in percentage of each item.

Table 5. The Percentage of Unfamiliar Topic Items

\begin{tabular}{|c|c|c|c|c|c|c|}
\hline & Item Description & 1* & 2 & 3 & 4 & 5 \\
\hline \multirow[t]{2}{*}{7} & I enjoy English & 0 & 5 & 17 & 8 & 2 \\
\hline & $\begin{array}{l}\text { reading when I } \\
\text { understand at least } \\
\text { some portion of the } \\
\text { text. }\end{array}$ & $0 \% * *$ & $15,62 \%$ & $53,12 \%$ & $25 \%$ & $6,25 \%$ \\
\hline \multirow[t]{2}{*}{8} & I do not prefer & 0 & 7 & 17 & 6 & 2 \\
\hline & $\begin{array}{l}\text { reading unfamiliar } \\
\text { topics, particularly in } \\
\text { the English language. }\end{array}$ & $0 \%$ & $21,87 \%$ & $53,12 \%$ & $18,75 \%$ & $6,25 \%$ \\
\hline \multirow[t]{2}{*}{9} & The most things I like & 0 & 7 & 14 & 8 & 3 \\
\hline & $\begin{array}{l}\text { to read in English are } \\
\text { short stories because } \\
\text { they have easy } \\
\text { words, and their } \\
\text { topics are common. }\end{array}$ & $0 \%$ & $21,87 \%$ & $43,75 \%$ & $25 \%$ & $9,37 \%$ \\
\hline \multirow[t]{2}{*}{10} & I feel anxious when I & 0 & 1 & 9 & 19 & 3 \\
\hline & $\begin{array}{l}\text { am reading a topic in } \\
\text { the English language } \\
\text { which I have no idea } \\
\text { about. }\end{array}$ & $0 \%$ & $3,12 \%$ & $28,12 \%$ & $59,37 \%$ & $9,37 \%$ \\
\hline
\end{tabular}

Note:

* 1 =strongly disagree; 2 =disagree; $3=$ neutral; $4=$ =agree; 5 =strongly agree

** The frequency in percentages was rounded to the nearest whole number

Based on the developed questionnaire by Ahmad et al. (2013), item 7-10 revolved around unfamiliar topic. 10 students (31\%) agreed with item 7 , which can be recognized that familiar topics are enjoyable in English reading. 8 students (25\%) agreed with item 8, which can be acknowledged that previous knowledge about the topic can ease reading in foreign language. 11 students (34\%) confirmed item 9, which can be understood that short stories are the preferred reading material in the English language 
for the students due to the familiarity which makes it interesting. The last is 22 students (69\%) confirmed item 10, which can be concluded that alien topics can cause reading anxiety in the English language.

The finding showed some students consider unfamiliar topic can decrease their interest in reading which can also cause reading anxiety. Unfamiliar topic can lose student's curiosity and make the students lazy to read. When the student tried to avoid reading English text, anxiety will grow within their self. This belief has similarity to what Kuru Gonen (2009), Zhao (2009), and Kim (2010) found. It clearly shows that the participants feel anxious if they read topics and do not understand it. In addition, the result of this study is in accordance with the theory from Wallace (2001, as cited in Kuru-Gonen, 2009), if the topic is unfamiliar for reader, it will make leaners uncomfortable in the reading process and hard to be effective reader.

\section{Unfamiliar Culture}

Table 6 below represents item description related with unfamiliar culture factors and frequency distributions in percentage of each item.

Table 6. The Percentage of Unfamiliar Culture Items

\begin{tabular}{|c|c|c|c|c|c|c|}
\hline & $\begin{array}{c}\text { Item } \\
\text { Description }\end{array}$ & 1* & 2 & 3 & 4 & 5 \\
\hline \multirow[t]{2}{*}{11} & In reading & 0 & 3 & 19 & 10 & 0 \\
\hline & $\begin{array}{l}\text { English, I hardly } \\
\text { understand the } \\
\text { idea if there is } \\
\text { more than one } \\
\text { meaning for } \\
\text { each word. }\end{array}$ & $0 \%{ }^{* *}$ & $9,37 \%$ & $59,37 \%$ & $31,25 \%$ & $0 \%$ \\
\hline \multirow[t]{2}{*}{12} & When I read & 0 & 3 & 13 & 14 & 2 \\
\hline & $\begin{array}{l}\text { English, I often } \\
\text { understand the } \\
\text { words, but I still } \\
\text { cannot quite } \\
\text { understand what } \\
\text { the writer says. }\end{array}$ & $0 \%$ & $9,37 \%$ & $40,62 \%$ & $43,75 \%$ & $6,25 \%$ \\
\hline \multirow[t]{2}{*}{13} & I usually & 0 & 7 & 7 & 15 & 3 \\
\hline & $\begin{array}{l}\text { translate word } \\
\text { by word when I } \\
\text { am reading }\end{array}$ & $0 \%$ & $21,87 \%$ & $21,87 \%$ & $46,87 \%$ & $9,37 \%$ \\
\hline
\end{tabular}




\begin{tabular}{|c|c|c|c|c|c|c|}
\hline & English. & & & & & \\
\hline \multirow[t]{2}{*}{14} & It is frustrating & 0 & 6 & 16 & 8 & 2 \\
\hline & $\begin{array}{l}\text { in reading } \\
\text { English when } \\
\text { one word is } \\
\text { connected with } \\
\text { another to } \\
\text { change the } \\
\text { meaning. }\end{array}$ & $0 \%$ & $18,75 \%$ & $50 \%$ & $25 \%$ & $6,25 \%$ \\
\hline \multirow[t]{2}{*}{15} & I most often feel & 1 & 9 & 16 & 5 & 1 \\
\hline & $\begin{array}{l}\text { that I cannot } \\
\text { understand an } \\
\text { English text even } \\
\text { though I know } \\
\text { every word's } \\
\text { meaning. }\end{array}$ & $3,12 \%$ & $28,12 \%$ & $50 \%$ & $15,62 \%$ & $3,12 \%$ \\
\hline
\end{tabular}

Note:

* 1 = strongly disagree; $2=$ disagree; $3=$ neutral; $4=$ =agree; $5=$ strongly agree

** The frequency in percentages was rounded to the nearest whole number

Based on the result on the table above, 10 students (31\%) agreed with item 11, which means student must consider the variety of meaning of each English word to connote the meaning accurately. 16 students (50\%) agreed with item 12, which can be acknowledged that knowing the words does not necessarily lead to understand the text. 18 students (56\%) confirmed item 13 which can be understood that regardless of knowing all vocabulary in the text, comprehension can't be guaranteed. Furthermore, 10 students (31\%) confirmed item 14, which can be acknowledged that connected words may change the meaning and this provoke anxiety in reading English. The last is 6 students (19\%) agreed with item 15, which can be understood that one may understand all the vocabulary but it can't guarantee the comprehension of text.

The finding showed if some students consider unfamiliar culture can inhibit their interest in reading which can also cause reading anxiety. Unfamiliar culture can lose student's curiosity of the text and make the students lazy to read. When the students are lazy to read, it could be anxiety provoking situation to some learners. This belief has similarity to what Kuru-Gonen (2009) and 
Razi (2004) found. This result is in accordance with theory proposed by Rajab et al. (2012), that unfamiliar with the culture implied in the text might hamper reading comprehension and elicit anxiety, since the text seem foreign to them. It represents that reading process is not only interaction between the reader and the thoughts of the author, but also interaction between the reader and the cultural knowledge which is implicitly stated in the text (Tomasello, 1999; as cited in Ahmad et al., 2013).

\section{Fear of Making Errors}

Table 7 below will represent item description related with fear of making error factor and frequency distribution in percentage of each item.

Table 7. The Percentage of Fear of Making Errors Items

$\begin{array}{llllll}\text { Item } & 1^{*} & 2 & 3 & 4 & 5\end{array}$

Description

\begin{tabular}{|c|c|c|c|c|c|c|}
\hline 16 & $\begin{array}{l}\text { I feel anxious in } \\
\text { reading aloud in } \\
\text { fear of making } \\
\text { errors. }\end{array}$ & $\begin{array}{c}0 \\
0 \%\end{array}$ & $\begin{array}{c}7 \\
21,87 \%\end{array}$ & $\begin{array}{c}15 \\
46,87 \%\end{array}$ & $\begin{array}{c}8 \\
25 \%\end{array}$ & $\begin{array}{c}2 \\
6,25 \%\end{array}$ \\
\hline 17 & $\begin{array}{l}\text { I feel } \\
\text { embarrassed in } \\
\text { front of others if } \\
\text { I pronounce a } \\
\text { simple and easy } \\
\text { word wrongly. }\end{array}$ & $\begin{array}{c}2 \\
6,25 \%\end{array}$ & $\begin{array}{c}2 \\
6,25 \%\end{array}$ & $\begin{array}{c}13 \\
40,62 \%\end{array}$ & $\begin{array}{c}13 \\
40,62 \%\end{array}$ & $\begin{array}{c}2 \\
6,25 \%\end{array}$ \\
\hline 18 & $\begin{array}{l}\text { I prefer to } \\
\text { prepare too } \\
\text { much and search } \\
\text { for the phonetic } \\
\text { transcript prior } \\
\text { to the class if I } \\
\text { was expected to } \\
\text { read in the class. }\end{array}$ & $\begin{array}{c}0 \\
0 \%\end{array}$ & $\begin{array}{c}8 \\
25 \%\end{array}$ & $\begin{array}{c}15 \\
46,87 \%\end{array}$ & $\begin{array}{c}9 \\
28,12 \%\end{array}$ & $\begin{array}{c}0 \\
0 \%\end{array}$ \\
\hline 19 & $\begin{array}{l}\text { I feel irritated if I } \\
\text { encounter a } \\
\text { word I do not } \\
\text { know how it is } \\
\text { pronounced. }\end{array}$ & $\begin{array}{c}0 \\
0 \%\end{array}$ & $\begin{array}{c}4 \\
12,50 \%\end{array}$ & $\begin{array}{c}17 \\
53,12 \%\end{array}$ & $\begin{array}{c}9 \\
28,12 \%\end{array}$ & $\begin{array}{c}2 \\
6,25 \%\end{array}$ \\
\hline 20 & $\begin{array}{l}\text { I prefer silent } \\
\text { reading rather } \\
\text { than reading }\end{array}$ & $\begin{array}{l}0 \\
0 \%\end{array}$ & $\begin{array}{c}2 \\
6,25 \%\end{array}$ & $\begin{array}{c}13 \\
40,62 \%\end{array}$ & $\begin{array}{c}14 \\
43,75 \%\end{array}$ & $\begin{array}{c}3 \\
9,37 \%\end{array}$ \\
\hline
\end{tabular}


aloud.

Note:

* 1 =strongly disagree; 2 =disagree; $3=$ neutral; 4 =agree; 5 =strongly agree

** The frequency in percentages was rounded to the nearest whole number

As the result above, item $16-20$ in the developed questionnaire by Ahmad et al. (2013) revolved around fear of making errors. 10 students (31\%) agreed with item 16, which proved that students attempt to avoid reading aloud because of fear of making errors. 15 students (47\%) confirmed item 17, which shows clearly the existence of anxiety in reading any word. Then, 9 students (28\%) agreed with item 18 can be assumed that students anxious more in term of pronunciation in reading. Furthermore, 11 students (34\%) agreed with item 19, which can be deduced that students worried about mispronouncing any word. The last is 17 students (53\%) confirmed item 20, which can be understood that students consider reading aloud as not enjoyable task.

It is evident that these participants avoided making errors in reading and understanding a text. In this study the participants expressed how they feel uncomfortable when they try to comprehend a text and pronounce the words in a text. In this study, fear of making errors is considered as the most frequent factor that causes reading anxiety under the aspect of personal factors, which means the result is in accordance with the theory proposed by Jalongo and Hirsh (2010) who contend that fears and phobias precipitated by reading tasks are a major impediment.

Furthermore, fear of making errors can be a consequence of having high expectations in learning to read. As stated by Horwitz et al. (1986) that anxious students cannot tolerate a less than perfect performance, as a result, they put unrealistic demands on themselves and think of any performance lower than their ideal one, as a failure. In this case, students seem to avoid making errors in pronunciation or misreading any word in the text.

\section{Worry About Reading Effect}

Table 8 below will represent item description related withworry about reading and frequency distribution in percentage of each item. 
Table 8. Worry about Reading Effect

\begin{tabular}{|c|c|c|c|c|c|c|}
\hline & $\begin{array}{l}\text { Item } \\
\text { Description }\end{array}$ & $1^{*}$ & 2 & 3 & 4 & 5 \\
\hline \multirow[t]{2}{*}{21} & \multirow[b]{2}{*}{$\begin{array}{l}\text { When I am } \\
\text { reading aloud, I } \\
\text { focus on reading } \\
\text { correctly rather } \\
\text { than focusing on } \\
\text { understanding } \\
\text { the text. }\end{array}$} & 0 & 6 & 17 & 10 & 0 \\
\hline & & $0 \%$ & $15,60 \%$ & $53,12 \%$ & $31,25 \%$ & $0 \%$ \\
\hline \multirow[t]{2}{*}{22} & \multirow{2}{*}{$\begin{array}{l}\text { In reading aloud } \\
\text { in the class, I do } \\
\text { not understand } \\
\text { the text even } \\
\text { though it is easy. }\end{array}$} & 2 & 10 & 17 & 1 & 0 \\
\hline & & $6,25 \%$ & $37,50 \%$ & $53,12 \%$ & $3,13 \%$ & $0 \%$ \\
\hline \multirow[t]{2}{*}{23} & \multirow{2}{*}{$\begin{array}{l}\text { I enjoy silent } \\
\text { reading because I } \\
\text { can easily } \\
\text { understand the } \\
\text { text. }\end{array}$} & 0 & 3 & 12 & 15 & 2 \\
\hline & & $0 \%$ & $9,37 \%$ & $37,50 \%$ & $46,87 \%$ & $6,25 \%$ \\
\hline \multirow[t]{2}{*}{24} & When reading & 0 & 5 & 18 & 8 & 1 \\
\hline & $\begin{array}{l}\text { English aloud in } \\
\text { the class, I focus } \\
\text { on word accent } \\
\text { rather than } \\
\text { understanding. }\end{array}$ & $0 \%$ & $15,62 \%$ & $56,25 \%$ & $25 \%$ & $3,12 \%$ \\
\hline \multirow[t]{2}{*}{25} & I get upset when & 0 & 5 & 16 & 9 & 2 \\
\hline & $\begin{array}{l}\text { I am not sure } \\
\text { whether I } \\
\text { understand what } \\
\text { I am reading in } \\
\text { English or not. }\end{array}$ & $0 \%$ & $15,62 \%$ & $50 \%$ & $28,13 \%$ & $6,25 \%$ \\
\hline \multirow[t]{2}{*}{26} & When reading & 0 & 7 & 20 & 3 & 2 \\
\hline & $\begin{array}{l}\text { English, I get } \\
\text { disturbed and do } \\
\text { not remember } \\
\text { what I have read. }\end{array}$ & $0 \%$ & $21,87 \%$ & $62,50 \%$ & $9,37 \%$ & $6,25 \%$ \\
\hline
\end{tabular}

Note:

* 1 =strongly disagree; 2 =disagree; 3 =neutral; 4 =agree; 5 =strongly agree

** The frequency in percentages was rounded to the nearest whole number 
Based on the result above, item 21-26 in the developed questionnaire by Al-Shboul et al. (2013) revolved around worry about reading effect theme.10 students (31\%) agreed with item 21 , which shows the phenomenon of worry about reading effect. Therefore, the students more concentrate on the act of reading rather than comprehending the text. Then, only 1 student $(3 \%)$ agreed and 12 students (44\%) rejected Item 22, which confirms that in some cases students can understand the text if it is an easy text.

Furthermore, 17 students (53\%) agreed with item 23, which proves that silent reading reduces worry about reading effect. 9 students $(28 \%)$ confirmed item 24 , which can be understood that students prefer focusing on performance rather than comprehension to avoid worry about reading effect. Worry about reading effect has proved that it can debilitate students' reading comprehension, as exemplified by 11 students (34\%) confirmed item 25 and 5 students (16\%) confirmed item 26.

Based on the finding showed that the participants showed a great concern of what their friends and teacher would react over their mistakes in reading aloud. This result is in accordance with the theory proposed by Jalongo and Hirsh (2010) who contend that reading aloud is a source of anxiety. It is described more that reading aloud is public speaking combined with the performance pressure of on-the-spot decoding accuracy, coupled with evaluation by teachers and peers (Lynch, 2000; cited in Jalongo and Hirsh, 2010).

No wonder, then, that when the students are called upon to read aloud in front of class, they concentrate on performance rather than comprehension. When they were asked again to deliver the gist of their reading, in most cases they would lose what has been read. Subsequently, when the students were not sure in answering the questions related to their reading, they might feel more anxious during and after the reading task which creates anxiety as cause of lack of performance and comprehension in reading. Congruent with the result of this study, the other studies conducted by Zhao (2009), Huang (2001), and Kuru-Gonen (2005, 2009) also revealed that worry about reading effect is a source of foreign language reading anxiety. 


\section{CONCLUSIONS AND SUGGESTIONS}

In response to the first research question, it came to the conclusion that over half of the students experience reading anxiety in which $71,9 \%$ of the students fell in the medium level and $9,4 \%$ of the students fell in high level. It was also relevant to the underlying theory that reading anxiety does exist, precisely anxiety happens when the learner try to decode or interpret a foreign language text.

Furthermore, for the second research question, it can be concluded that in this study, anxiety in reading was provoked by two broad aspects namely text features and personal factors. Under the concept of text feature, unknown vocabulary was considered as the most frequent factor that contribute to reading anxiety. It was followed by unfamiliar topic as the second most frequent factor. Then, unfamiliar culture was considered as the least factor that contributes to reading anxiety. Meanwhile, under the concept of personal factor, fear of making errors was ranked as the most frequent factor and then followed by worry about reading effect as the least factor. Therefore, it is necessary for English teachers to take those potential factors of anxiety into consideration in teaching their students, since reading anxiety may impede comprehension while reading in English as foreign language.

Regarding suggestions for further studies, as both levels and sources of reading anxiety may vary in many different contexts, more studies are called for with different groups of learners in various situations to better understand the issue of English reading anxiety. In addition, further investigation towards strategies to cope with reading anxiety are also necessary for further studies to assist both teachers and students in foreign language reading process.

\section{SHORT BIOGRAPHY}

Azhari Muhlis was born in Bandar Lampung on September $7^{\text {th }}$ 1992. He is alumnus of Indonesia University of Education, Bandung, Indonesia. Now, he is a master graduate student of English Education Department at Sebelas Maret University, Surakarta, Indonesia. The writer's main interest is doing research related to foreign language acquisition. In this opportunity, the 
writer of this paper is interested to publish an article entitled "Foreign Language Reading Anxiety among Indonesian EFL Senior High School Students" that will be published in English Franca: Academic Journal of English Language and Education of STAIN Curup.

\section{REFERENCES}

Ahmad, I. S., Al-Shboul, M. M., Nordin, M. S., Rahman, Z. A., Burhan, M., Madarsha, K. B. (2013). The potential sources of foreign language reading anxiety in a Jordanian EFL context: A theoretical framework. English Language Teaching, 6(11), 89110. doi: 10.5539/elt.v6n11p89.

Al-Shboul, M. M., Ahmad, I. S., Nordin, M. S., Rahman, Z. A. (2013). Foreign language reading anxiety in a Jordanian EFL context: A qualitative study. English Language Teaching, 6(6), 1-19. doi: 10.5539/elt.v6n6p38.

Brantmeier, C. (2005). Anxiety about L2 reading or L2 reading tasks? A study with advanced language learners. The Reading Matrix, 5(2), 67-85. Retrieved from cbrantme@artsci.wustl.edu.

Brown, D. (2007). Principles of language learning and teaching (5th ed.). United States of America: Pearson Longman.

Creswell, J. W. (2009). Research design: Qualitative, quantitative, and mixed methods aprroaches. Los Angeles: Sage.

Creswell, J. W. (2012). Educational research: planning, conducting, and evaluating quantitative, and qualitative research. (Fourth edition). United States of America: Pearson Education. Inc.

Horwitz, E.K. (2001). Language anxiety and achievement. Annual Review of Applied Linguistics, 21, 112-126.

Horwitz, E.K., Horwitz, M.B., \& Cope, J. (1986). Foreign language classroom anxiety. The Modern Language Journal, 70(2), 125132. Retrieved from http://www.jstor.org/stable/327317

Huang, H.Y. (2001). Chinese university foreign language students' anxiety about reading in English. (Doctoral dissertation). Retrieved from Proquest Dissertation and Theses. (UMI 3051922) 
Jalongo, M. R., \& Hirsh, R. A. (2010). Understanding reading anxiety: New insights from neuroscience. Early Childhood Education Journal, 37, 431-435. doi: 10.1007/s10643-010-0381-5

Kim, H.O. (2012). Factors associated with foreign language reading anxiety in the university academic setting. English Language and Linguistics, 18 (2), 27-48. Retrieved from hokim67@ajou.ac.kr

Kuru-Gonen, S. I. (2007). L2 reading anxiety: Exploring the phenomenon. In K. Bradford-Watts (Ed.), JALT2006 Conference Proceedings. Tokyo: JALT.

Kuru-Gonen, S. I. (2009). The sources of foreign language reading anxiety of students in a turkish EFL context. Paper presented at the 5th WSEAS/IASME International Conference on EDUCATIONAL TECHNOLOGIES (EDUTE' 09), Spain.

Liu, Y. H. (2011). Syntactic differences and foreign language reading anxiety: An investigation of Taiwanese university students. (Unpublished Doctoral dissertation). The Ohio State University, Columbus, Ohio, United States.

Rajab, A., Zakaria, W.Z.W., Rahman, H.A., Hosni, A.D., Hassani, S. (2012). Reading anxiety among second language learners. Procedia - Social and Behavioral Sciences, 66, 362-369.

Saito,Y., Horwitz, E.K, \& Garza,T.J. (1999). Foreign language reading anxiety. The Modern Language Journal, 83, 202-218.

Sellers, V. (2000). Anxiety and reading comprehension in Spanish as a foreign language.Foreign Language Annals, 33, 512-521.

Utami, B.A.P. (2007). Reading anxiety of the students of management economics faculty of Sanata Dharma university. (Unpublished Bachelor's paper). Sanata Dharma University, Yogyakarta.

$\mathrm{Wu}, \mathrm{H}$. J. (2011). Anxiety and reading comprehension performance in English as a foreign language. Asian EFL Journal, 13(2), 273-307.

Young, D. (2000). An investigation into the relationship between L2 reading anxiety and $\mathrm{L} 2$ reading comprehension, and selfreported level of comprehension topic familiarity features of an L2 text and reading ability in the L1 and L2. Current Research on the Acquisition of Spanish (Eds.). Ron Leow \& Cristina Sanz. Summerville: Cascadilla Press. 
Zbornik, J. (2001). Reading anxiety manifest itself emotionally, intellectually. Retrieved from http://www.lakewoodcityschools.com.

Zhao, A. (2008). Foreign language reading anxiety: Investigating English-speaking university students learning chinese as a foreign language in the United States. Electronic Theses, Treatises and Dissertations. Retrieved from http://diginole.lib.fsu.edu/etd. 